\title{
CONTRA LA CONFIANZA LEGÍTIMA COMO LÍMITE A LA INVALIDACIÓN DE ACTOS ADMINISTRATIVOS
}

\author{
AGAINST THE PRINCIPLE OF PROTECTION OF LEGITIMATE \\ EXPECTATIONS
}

\section{RAÚl LETELIER WARTENBERG*}

\begin{abstract}
RESUMEN: El presente estudio aborda de una manera crítica el llamado principio de protección a la confianza legítima como límite a la potestad invalidatoria de la Administración pública mostrando las incoherencias de su construcción y proponiendo un posicionamiento diverso de los intereses que dicho principio pretende proteger.
\end{abstract}

Palabras clave: Confianza legítima, buena fe, invalidación, seguridad jurídica, principios jurídicos.

ABSTRACT: This paper reflects in a critic way about the so called principle of protection of legitimate expectations as a limit to the power of the Government to quash its own unlawful administrative acts. It will show the inconsistence of this construction proposing another way to allocate the interests that this principle wants to protect.

Key words: Principle of legitimate expectations, good faith, revocation, legal certainty, principles.

\section{INTRODUCCIÓN}

Desde hace algo de tiempo, algunos autores han instalado en el debate del Derecho Administrativo chileno el que un principio comúnmente llamado "protección a la confianza legítima” actuaría como una especie de límite a la potestad administrativa de invalidación de actos administrativos. En el ambiente nacional han sido principalmente los excelentes trabajos de Jorge Bermúdez ${ }^{1}$ y Javier Millar ${ }^{2}$ los que han insistido en esta idea de manera específica ${ }^{3}$. Por su parte, la Contraloría General de la República ha recogido también este razonamiento en diversos dictámenes ${ }^{4}$.

\footnotetext{
* Profesor de Derecho Administrativo, Universidad Alberto Hurtado. Correo electrónico: rletelier@uahurtado. cl. Licenciado en Ciencias Jurídicas, Universidad Católica de Valparaíso; Máster y Doctor en Derecho, Universidad Carlos III de Madrid.

1 Bermúdez (2005).

2 Millar (2003).

3 En los inicios de la discusión sobre invalidación administrativa y en su posterior desarrollo hay también importantes aportes al respecto. Véase Olguín Juárez, H. (1961); Soto Kloss, E. (1989) pp. 475 y sgtes.; OelcKers Camus, O. (1978) pp. 121 y sgtes.; Vargas Zincke, O. (1995) pp. 35 y sgtes; Marín Vallejo, U. (2000) pp. 45 a 60; Reyes Riveros, J. (2002); Letelier, R. (2002) pp. 43 y sgtes.; Jara Schnettler, J. (2004); Dorn Garrido, C. y Salinas Bruzzone, C. (2006) pp. 259 y sgtes.; Ferrada Bórquez, J.C. (2007) pp. 131 y sgtes.

4 Véase Dictámenes Nos 38.825 de 2013, 53.290 de 2004, 49.531 y 2.965, ambos de 2008; y 4.212 y 75.915 , ambos de 2011, entre otros. Un estudio sobre esta línea de jurisprudencia administrativa en BoETTIGER (2009) pp. 309 y sgtes. Esta línea de razonamiento sostenida por la CGR, sin embargo, se desarrolla en paralelo a otra
} 
Como sabemos, el art. 53 de la Ley 19.880 de Bases de los Procedimientos Administrativos (en adelante LBPA) estableció que "la autoridad administrativa podrá, de oficio o a petición de parte, invalidar los actos contrarios a derecho", y que dicha facultad estará afecta a dos limitaciones, debe practicarse "previa audiencia del interesado" y "dentro de los dos años contados desde la notificación o publicación del acto”.

Los referidos autores, sin embargo, estiman que esa potestad invalidatoria no solo estaría limitada por aquellas dos circunstancias establecidas expresamente en la ley sino que ella no podría afectar a los interesados que tienen una confianza legítima en la estabilidad de la decisión administrativa presuntamente ilegal ${ }^{6}$.

Según Bermúdez, existiría en el ordenamiento jurídico una especie de necesidad de permanencia en la regulación y aplicación de las normas jurídicas la cual obligaría a la Administración a actuar de manera que no provoque una alteración en la interpretación que ella misma viene dando a las normas o un cambio en la manera de regular o de resolver. A este respecto, la Administración solo estaría legítimamente autorizada para realizar esos cambios "si respeta, entre otros, la confianza que los administrados tienen en su forma o dirección de la actuación" 7 .

Desde otra perspectiva, lo que se pretendería proteger no sería solo una especie de invariabilidad de las decisiones públicas sino también una suerte de buena fe de los administrados que confían legítimamente que aquellas decisiones que les han entregado ciertas ventajas o derechos se mantendrán en el tiempo.

Resumiendo, estos serían los argumentos sostenidos por los referidos autores para justificar este supuesto límite a la potestad invalidatoria:

1. Inclusión Constitucional. Según Bermúdez, el principio jurídico de protección a la confianza legítima se encontraría consagrado a nivel constitucional, pues este sería "de-

que desarrolla el ente contralor en que reafirma fundadamente la extensión sin límites de la potestad invalidatoria. Vésae Dictámenes Nos 32.350 de 2003, 71.415 de 1968, 16.211 de 1979; 917 y 17.799 de 1990, entre otros. Estas líneas de argumentación diversas y contrapuestas muestran principalmente el conflicto para el órgano contralor entre los efectos de una invalidación (en tanto necesariamente retroactiva y que defrauda confianzas legítimas y afecta posiciones patrimoniales) y la restricción en el ejercicio de la potestad invalidatoria. Tal como sostendremos al fina de este texto, lo uno no conlleva necesariamente lo otro.

5 Entiendo la regla de caducidad y la audiencia del afectado como límites en tanto restringen un uso libre de la potestad. Ambas reglas, sin embargo, pueden ser también entendidas como la simple regulación de la potestad invalidatoria.

${ }^{6}$ Podría también entenderse esta corriente como una continuación (más sofisticada, eso sí) del pensamiento esbozado por Soto Kloss cuando antes de la ley 19.880 estimaba posible el ejercicio de la potestad invalidatoria por parte de la Administración pero añadiendo que "es jurídicamente improcedente el ejercicio de tal potestad invalidatoria por parte de la Administración si el acto administrativo ilegal ha producido efectos y ellos han ingresado al patrimonio de terceros de buena fe, ya que los errores de la Administración deben ser soportados por ella misma y jamás ser cargados a terceros enteramente ajenos a su torpeza (nemo auditur propriam turpitudinem allegans), y además habiéndose producido los efectos jurídicos del acto defectuoso dichos efectos devienen adquiridos y, por tanto, protegidos y asegurados por la propia Constitución (art. $19 \mathrm{n}^{\circ} 24$ y art. 20 inc. $1^{\circ}$ ), pues para sus beneficiarios constituyen un derecho de propiedad”. Sото KLoss (1989) p. 485.

7 Bermúdez (2005) p. 85. 
ducido" "desde los principios constitucionales de Estado de Derecho (arts. 5, 6 y 7 CPR) y de seguridad jurídica (art. 19 N² 26 CPR)".

2. Deducción de la teoría de los actos propios y de la necesidad de proteger la confianza que las personas ponen en sus instituciones jurídicas. Este grupo de argumentos enfatizan lo importante que es proteger las expectativas que los ciudadanos poseen del ordenamiento jurídico. Como normalmente se repite que no hay mercado sin confianza, esas expectativas que los ciudadanos tienen de la interpretación de las reglas que los gobiernan deben ser protegidas.

3. Concepción amplia del principio de legalidad. Según esta idea le estaría "vedado a la Administración Pública actuar en ejercicio de sus potestades de manera abusiva (arbitraria) o en exceso de poder" lo cual supuestamente sucedería cuando la Administración altera la interpretación de una norma o cambia la manera de regular o resolver, no respetando "la confianza que los administrados tienen en su forma o dirección de la actuación" ${ }^{\text {. }}$

4. Contravención a las facultades de la Contraloría General de la República. Según Bermúdez para aquellos actos de los cuales la Contraloría ha tomado razón, la invalidación solo procedería para el caso en que "la aplicación práctica del acto demuestre que esta adolece de una ilegalidad sobreviniente y producto de un cambio en el ordenamiento jurídico, no prevista al momento del trámite de toma de razón”. Para los demás casos, esto es, para aquellos en donde la ilegalidad que la Administración constata se considere presente desde que el acto fue dictado, no procedería tal invalidación. Lo contrario implicaría suponer "un control indirecto (...) por parte de la Administración activa, de una potestad exclusiva de la Contraloría General de la República" .

5. Protección a la buena fe tanto de los inmediatamente interesados en el acto como de terceros. Esta idea de protección a la buena fe parece ser uno de los argumentos más fundamentales a la hora de argumentar en favor de este principio. En este sentido, Millar ha entendido que "el verdadero límite a la invalidación viene dado por la protección de la buena fe de terceros afectados con la apariencia de regularidad de la situación provocada por el acto ilegal. Solo a estos y siempre que, estando de buena fe, el acto haya provocado efectos a su respecto podría hacer excepción la invalidación" ${ }^{10}$. Algunas veces, es posible encontrar que, derivada de esta idea de buena fe, puede encontrarse otro interés a perseguir como es la simple seguridad o certeza jurídica.

La manera como se ha construido esta supuesta limitación a la potestad invalidatoria es, a mi parecer, incorrecta. En efecto, diversos son los problemas que este razonamiento esconde y su construcción responde más bien a un análisis parcial de los bienes que se encuentran en juego en el ejercicio de una competencia invalidatoria. Este trabajo pretende justificar esta aseveración.

\footnotetext{
8 Bermúdez (2005).

9 Bermúdez (2005) p. 100

10 Millar (2003) p. 97
} 
No haré una reconstrucción sistemática del principio de confianza legítima. Esta empresa ha sido realizada de manera exitosa por diversos autores ${ }^{11}$. En el presente trabajo solo haré referencia a algunas características particulares del proceso de consolidación del principio, para luego realizar diversas críticas a su construcción como límite a la invalidación administrativa. Finalmente, me permitiré hacer un par de recomendaciones para compatibilizar los intereses en juego en la construcción del principio de confianza legítima con los intereses presentes en la potestad invalidatoria.

\section{PRELIMINARES. GRANDES CASOS HACEN MAL DERECHO. EL CASO DE LA VIUDA DE BERLÍN}

Hace ya más de 100 años el juez norteamericano Oliver Wendell Holmes, uno de los más grandes juristas del siglo XX, concluía en un voto disidente que "great cases, like hard cases, make bad law" ${ }^{12}$. Con esa fórmula, quería significar que deducir reglas generales de soluciones muchas veces contaminadas por la extremada particularidad de un caso conducía normalmente a resultados desafortunados. Estos grandes casos -indicaba Holmes- "no lo son en razón de su importancia para configurar el derecho futuro sino por la accidentalidad de aquellos incontenibles intereses que, apelando a los sentimientos, distorsionan la decisión judicial. Aquellos intereses inmediatos ejercen una suerte de presión hidráulica que hace que aquello que antes era claro parezca ahora dudoso, que aquello que antes eran principios estables de derecho comiencen ahora a acomodarse a la situación"13. El nacimiento del principio de confianza legítima como supuesto límite a la invalidación es precisamente un caso de este tipo.

Resulta más o menos compartido, el entender que el llamado "caso de la viuda de Berlín” comportó la primera vez en que el principio de protección a la confianza legítima fue reconocido judicialmente bajo el nombre alemán de Vertrauensschutzprincipz por el Oberverwaltungsgericht de Berlín ${ }^{14}$. En este caso, a una viuda de avanzada edad la Consejería del Interior de Berlín le había reconocido un derecho a recibir una específica pensión si es que se trasladaba desde la República Democrática de Alemania a Berlín occidental. Sobre la base de este reconocimiento, la viuda hizo efectivo el traslado, gastando fuerzas y dinero en realizar esa mudanza. Luego de algún tiempo, la Administración se percató que la viuda no tenía derecho a tal pensión pues no cumplía los requisitos legales para ser beneficiaria. De acuerdo a esto, le exigió la devolución de las sumas pagadas ordenándose también no seguir pagando la referida pensión ${ }^{15}$. El tribunal administrativo superior decidió en 1956 que en el caso referido no procedía la devolución de las cantidades ya pagadas ni tampoco la revocación del acto que asignó la pensión. La Administración no solo no podía recuperar

\footnotetext{
11 Especialmente recomendable es el texto de GARCía LuENGO (2002). Junto a este, puede también consultarse Castillo Blanco (1998), Schwartze (1992) y Shønberg (2000).

12 Northern Securities Co. v. United States [1904] 193 U.S. 197.

13 Northern Securities Co. v. United States [1904] 193 U.S. 197.

14 La sentencia puede consultarse en Die öffentliche Verwaltung (DÖV) 1957, n² 27, pp. 753-756.

15 Sobre el caso, véase Maurer (2004) p. 290 y ss.
} 
lo que había concedido de manera ilegal sino que debía seguir pagando la asignación. Debía así protegerse la confianza legítima de la viuda de Berlín.

A partir de aquella decisión, la conceptualización alemana de este interés a proteger se extendió a diversos ordenamientos jurídicos y se fortaleció su reconocimiento en la propia realidad germana. De entre aquellos ordenamientos donde este principio migró, el más importante fue el comunitario que acogió esta idea aplicándola en diversos fallos ${ }^{16}$. Una vez que este principio se "comunitarizó" 17 , su transferencia a las decisiones judiciales de los estados de la unión fue rápida y con algo de impacto.

Sin embargo, al poco tiempo, su uso no continuó expandiéndose en el ámbito de la invalidación o revocación de actos administrativos ilegales sino que su aplicación se concentró con mayor fuerza en la esfera de las modificaciones normativas, esto es, en cambios regulares de la legislación y en la aplicación retroactiva de esos cambios. En este campo, el principio en examen pretendía proteger a los ciudadanos de que las confianzas depositadas en determinadas normas puestas en el ordenamiento jurídico en un momento específico no fueran vulneradas por cambios intempestivos en la regulación. El caso Sofrimport ${ }^{18}$-asunto en el que, curiosamente, manzanas chilenas fueron las protagonistas- fue un ejemplo de esta aplicación. La empresa Sofrimport importaba nuestras manzanas al mercado europeo y para ello se había provisto de una licencia de importación de conformidad al Reglamento 346/88 que a la sazón era la norma vigente en la comunidad europea. Un reglamento posterior tomó fuertes medidas proteccionistas suspendiendo las licencias otorgadas para estas manzanas. Sin embargo, sucedió que a la fecha de cambio del reglamento las manzanas chilenas ya se encontraban "en tránsito", por lo que al llegar estas a puerto no le fue permitido a la empresa ingresarlas. Mediante una acción de anulación el Tribunal de Justicia de las Comunidades Europeas (en adelante TJCE) estableció que la Comisión, al no disponer de una regulación diversa para los productos "en tránsito" violó la confianza legítima del importador declarando nulas las regulaciones y prohibiciones en lo referente a ese tipo de productos.

Este tipo de casos, junto a otros similares, fueron marcando el principal uso que se le dio al principio de protección de la confianza legítima al menos en el ambiente europeo $^{19}$. Tal como se ha indicado, lo que se protegía era la buena fe de un administrado ante un cambio normativo perfectamente legal que le perjudicaba y respecto del cual no había tenido posibilidad de prepararse. En esta situación se custodiaba principalmente que los cambios normativos no tuviesen efectos retroactivos a situaciones ya consolidadas o que

\footnotetext{
16 Sobre sentencias que han reconocido el principio de protección de la confianza legitima, véase WolfF, BAchof y Stober (2004) p. 895; Craig y de BúrCa (2003) p. 380 y ss. Una vía importante de transferencia se realizó a través de las opiniones de los abogados generales que portaban parte de su formación nacional al derecho comunitario. Mediante la consagración del principio a nivel comunitario se siguió luego el proceso de transferencia inverso, véase SCHWARTZE (1992) p. 939.

17 Proceso que por lo demás se desarrolló sin la necesidad para los jueces de buscar las bases del derecho comunitario o comparado en las cuales fundar este principio. Bastó al parecer solo la apelación a que estos principios se encontraban implícitos en el derecho europeo, véase SCHWARZE (1992) p. 938.

18 Caso C-152/88 Sofrimport Sàrl v. Commission [1990] ECR 2477.

19 Otros casos similares, véase CRAIG y de BúrCA (2003) p. 385.
} 
se habían generado con la confianza de estar cumpliendo la ley ${ }^{20}$. Por su parte, en el área de los actos ilegales, y principalmente en lo referente a la potestad de invalidación, como indica Craig y de Burcá, dos fueron las principales tendencias en materia de invalidación o revocación de este tipo de actos. En primer lugar se entendió que un retardo no razonable de la Administración en realizar esa invalidación puede actuar como límite a ella. Esto, por lo demás, no era otra cosa que la aplicación de un antiguo precedente francés del Conseil d'Etat que restringía la facultad invalidatoria al plazo del recurso contencioso-administrativo de nulidad ${ }^{21}$.

En segundo lugar, en lo que se refiere a los efectos retroactivos de la invalidación, se indicaba que debía realizarse un balance entre el interés público en la legalidad y el interés privado en la seguridad jurídica ${ }^{22}$. Cabe indicar que, por regla general, este tipo de fundamentaciones se aplicaron en acciones indemnizatorias más que en impugnaciones de revocaciones de actos administrativos.

Así las cosas y luego del transcurso de algo de tiempo, los propios tribunales alemanes también fueron concentrando su uso ya no en cuestiones de ilegalidad sino en los mismos problemas de retroactividad de las leyes ${ }^{23}$.

Por su parte, el contenido que le asignó a este principio la jurisprudencia comunitaria fue desde sus comienzos oscilante y en gran parte de la jurisprudencia su inclusión en el razonamiento judicial fue precisamente para rechazarlo como fundamento de la sentencia ${ }^{24}$. El uso del argumento por el TJCE es por lo demás paradójico y revela las disputas competenciales existentes en ese orden y la utilización de este tipo de argumentos para hacer ejecutables a cualquier precio las obligaciones comunitarias. En efecto, mientras algunas sentencias confirman la utilización de este argumento para limitar los poderes de los estados nacionales en los cambios normativos que estos acuerdan, no sucede lo mismo cuando lo que se pretende limitar son los poderes de las propias instituciones europeas. Es así como el TJCE ha estimado que "las instituciones comunitarias disponen de un margen de apreciación para la elección de los medios necesarios para la realización de su política, sin que los agentes económicos estén autorizados a utilizar la confianza legítima como medio

\footnotetext{
20 SCHWARZE (1992) pp. 979 y ss.

21 Véase arrêt Dame Cachet de 3 de noviembre de 1922. Con el arrêt Termon, de 26 de octubre de 2001, se ha disociado el plazo de invalidación con el del recurso de nulidad quedando el primero en 4 meses. Esto se aplica para actos que tienen por objeto crear derecho.

22 Craig y de Búrca (2003) p. 387.

23 Véase BVerfGE 30, 367; 30, 392 y 39, 128.

24 Véase, por todos, casos 2/75 Einfuhr-und Vorratsstelle für Getreide und Futtermittel v. C. Mackprang [1975] ECR 607; 265/85 Van den Bergh v. Commission of the European Communities [1987] ECR 1155; C-331/88 The Queen v. Minister of Agriculture, Fisheries and Food and Secretary of State for Health, ex parte: Fedesa and others [1990] ECR 4023; C-350/88 Société française des Biscuits Delacre v. Commission of the European Communities [1990] ECR 395; C-104/97P Atlanta AG v. Commission and Council [1999] ECR 6983; C-110/97 Netherlands v. Council [1997] ECR 1795; C-402/98 ATB v. Ministero per le Politiche Agricole [2000] ECR 5501; C-179/00 Gerald Weidacher v. Bundesminister für Land-und Forstwirtschaft [2002] ECR 501.
} 
de mantener una situación existente, puesto que esta puede ser modificada por decisiones adoptadas por las instituciones comunitarias en el marco de su poder de apreciación” 25 .

Por otra parte, la actitud que el TJCE ha tomado frente al argumento de la confianza legítima es claramente restrictivo y la explicación de este temor proviene -como ha indicado certeramente García Macho- "del carácter perturbador que este principio tiene frente a los objetivos de los poderes públicos, e incluso porque puede cuestionar otros principios generales, especialmente el de legalidad". "Por ello, solamente se considera infringida la confianza legítima cuando la medida normativa tomada es legal, pero hasta tal punto desestabilizadora que rompe los límites razonables en las relaciones entre la Administración y los administrados"26.

Como puede percibirse hasta ahora, la gestación del principio de confianza legítima no ha sido en manera alguna pacífica y su desarrollo se encuentra al día de hoy en una fase de franco posicionamiento no ya en la esfera de la invalidación administrativa sino principalmente en el campo de las variaciones normativas y en la regulación de las transiciones entre regulaciones. En esta última construcción, poco queda de la primitiva formulación del principio edificado, como ya hemos indicado, sobre la base de una casuística solución de un asunto difícil.

\section{INFLACIÓN DE NORMAS CONSTITUCIONALES}

El uso de normas constitucionales para justificar opciones regulatorias que nos parecen mejores que las actualmente vigentes es una técnica común en los tiempos que corren. La posterior "aplicación directa" de ese contenido prefabricado es además vista con buenos ojos por muchos ${ }^{27}$. La forma en que opera este razonamiento es bastante sencilla. Como las cláusulas constitucionales son de una amplitud extrema debemos llenar de contenido conceptos jurídicos indeterminados para luego, una vez que hemos "constitucionalizado" aquel contenido que nos parecía correcto y coherente, poder oponerlo ya sea como regla jerárquica superior y así justificar la invalidez de una norma legal o ya sea, de una manera menos invasiva, entendiendo que aquel contenido constitucionalizado interviene como forma de delimitación del ámbito de aplicación de una determinada norma jurídica legal.

En este contexto, no es difícil percibir como diversos autores consideran "a priori" que la potestad invalidatoria de la Administración no se ejerce de manera óptima o razonable cuando afecta un determinado estado personal de confianza en la estabilidad de una posición o situación determinada. Asumido este deseo, incluir esa limitación en conceptos jurídicos indeterminados como el de "Estado de Derecho" (supuestamente incluido en los arts. 5, 6 y 7 de la CPR) o el de "seguridad jurídica" (también supuestamente incluido en art. $19 \mathrm{~N}^{\circ} 26 \mathrm{CPR}$ ) aparece como una buena forma para luego oponer ese contenido a la

\footnotetext{
${ }_{25}$ Caso 52/81 Offene Handelsgesellschaft in Firma Werner Faust contra Comisión de las Comunidades Europeas [1982] ECR 3745.

26 García Macho (1987) p. 572.

27 En general, la oposición entre una aplicación directa de la Constitución y su comprensión como un mero documento programático ha sido puesta relieve desde hace bastante años con una amplia recepción en doctrina. Véase García de Enterría (2006).
} 
regulación legal. Esta técnica, por lo demás, no es solo propia de nuestro entorno. En otras latitudes se ha considerado al principio de buena fe, en tanto fundamento de la protección de la confianza, ni siquiera como derivación de textos legales sino como una necesidad de corrección inmanente al ordenamiento jurídico ${ }^{28}$. O la referida protección se ha deducido también del principio de igualdad ${ }^{29}$ o del de libertad ${ }^{30}$.

No será este el lugar de analizar con detención los argumentos y objeciones de cada una de estas justificaciones. Valgan, sin embargo, las siguientes prevenciones sobre algunas de ellas.

\subsection{LA LEY Y EL ESTADO DE DERECHO}

La deducción de una regulación deseada desde la idea de "Estado de Derecho" es una técnica de sencilla utilización pero que posee problemas argumentativos estructurales. En efecto, ella se comporta como una apelación final sin justificación consiguiente ${ }^{31}$. Es decir, se dice normalmente que algo deriva de la idea de Estado de Derecho y se llega hasta ahí, sin siquiera tratar de justificar que ese concepto -que por lo demás ya infunde el suficiente temor de investigar sobre él- tenga un contenido tal que nos permita encontrar aquella regulación buscada. No es este tampoco el momento de hacer una crítica general a esta forma de trabajar con el derecho. Ya Hedemann señaló en su tiempo los peligros de llevar el razonamiento jurídico a un ajuste mediante cláusulas generales con contornos poco claros. Este ejercicio, indicaba aquel autor, lo único que logra es depreciar una correcta argumentación jurídica y convertir a estas reglas en armas arrojadizas que pueden ser utilizadas para obtener los resultados que se quiera previamente conseguir ${ }^{32}$.

Por su parte, la asociación entre nuestro principio y el Estado de Derecho ha sido especialmente fecunda en la doctrina alemana, acostumbrada a la técnica de incluir intereses en conceptos jurídicos indeterminados dejando a salvo el método interpretativista como forma de indagar acerca de lo que dice supuestamente el Derecho ${ }^{33}$. En este sentido, se suele indicar que uno de los requerimientos de la vida en sociedad es que los órganos establecidos para la organización sean capaces de proveer condiciones de previsibilidad y certeza que le permitan al ciudadano moverse con seguridad en la sociedad, o que seguridad jurídica y buena fe poseen una matriz idéntica ${ }^{34}$. Este tipo de interés, por lo demás muy similar a los tipos de intereses o valores que pretenden concretizarse mediante la política, se subentienden como perteneciente al derecho y, en tanto tal, hábiles para resolver casos concretos en donde se presenten aquellas necesidades.

\footnotetext{
28 Véase Merusi (1991).

29 Sobre este último, véase GarCía LuENGo (2002) p. 159 y sgtes.

30 Principalmente, Gravitz (1973) p. 675 y sgtes.

31 Vésae su uso en Bermúdez (2005) p. 84, 96.

32 Hedemann (1933) p. 66 y sgtes. En un sentido similar y específicamente usando el concepto de Estado de Derecho, véase Maravall (2003) p. 273 y sgtes.

33 Véase MainKa (1963) p. 29 y sgtes. Un análisis de la estructura de este razonamiento, véase Blanke (2000)

p. 76 y sgtes.

34 Ossenbühl (1972) p. 27.
} 
Sin embargo, tal como indicábamos, resulta bastante difícil buscar por qué la noción de Estado de Derecho produce realmente aquel efecto que se le imputa. Tanto el antiguo concepto de Rechtsstaat como el de Rule of Law vinieron a significar ideas de síntesis de los compromisos liberales acordados luego del término del antiguo régimen. La existencia de las herramientas básicas para la tutela de los derechos fundamentales y la consagración de una separación de los poderes comportó un nuevo estado de cosas que es concebido bajo la expresión de "Estado de Derecho". Y esto último, entendido por muchos como la versión fuerte o sustantiva del concepto en contraposición a la versión débil o formal en la cual lo único relevante es que los poderes públicos hayan sido conferidos por la ley y ejercidos en la forma de acuerdo a ella ${ }^{35}$. Frente a la arbitrariedad del monarca se contrapone la primacía de la ley formal y sustantiva como sistema de reglas impersonales, abstractas, generales y no retroactivas ${ }^{36}$. Este punto es llevado a su máxima expresión en el État de droit francés en donde el vector más dinámico y caracterizador de la noción es precisamente la soberanía popular en donde la ley (y con ello la legalidad) es considerada como la expresión de la voluntad general de la nación a cuyas prescripciones todo poder debe rigurosamente atener$\mathrm{se}^{37}$. En un sentido algo similar, la consolidación teórica de Dicey de la idea de Rule of Law viene a colocar esa idea al lado de la primacía del Parlamento, y con ello, de la legalidad generada por él, como los principios matrices de la constitución británica ${ }^{38}$. Y ello incluso, como afirma algún autor, no porque este principio de primacía haya sido inventado por los jueces, sino porque él ha sido aceptado a través de los siglos por jueces y por todos los órganos oficiales involucrados en la operacionalización del sistema constitucional inglés ${ }^{39}$. Así las cosas, desde los orígenes -incluso clásicos ${ }^{40}$ - de la idea de Estado de Derecho, una base mínima de su contenido está dada por la consagración de la ley como herramienta primera para delimitar y controlar al poder ${ }^{41}$. En este escenario, las garantías mínimas que han operado como limitación a la legislación han sido documentos tan fundacionales como la Carta Magna de 1215, el Habeas corpus, la abolición de la tortura, la Petition of Rights de 1628, la Constitución norteamericana, la Declaración de Derechos del Hombre y del Ciudadano francesa de 1789 y la Declaración Universal de Derechos Humanos de 1948, entre otros. Estos instrumentos son los que han servido de base para la consagración del Estado de Derecho toda vez que concretizan las reglas básicas del juego democrático ${ }^{42}$. Estas garantías, no obstante, no poseen respuestas para todas las problemáticas de la sociedad. La gran mayoría de las interrogantes deben ser resueltas ex novo, sin antecedentes ni consideraciones previas sino mediante la compleja valoración de intereses contrapuestos. Un sistema de invalidación de actos administrativos es precisamente una regulación de este último tipo. La síntesis de los intereses en juego hace optar al órgano de legitimación democrática por

35 Esta clasificación en Ferrajoli (2006) p. 349.

36 Zolo (2006) p. 22.

37 Zolo (2006) p. 28.

38 DiCEY (1982) pp. 107 y sgtes.

39 Bingham (2010) p. 167.

40 Aristóteles, Política, 1286-1287.

41 Véase Tamanaha (2004) pp. 114 y sgtes.

42 Véase Bingham (2010) pp. 10 y sgtes. 
un determinado modelo, y ninguna de las opciones posibles puede ser revisada bajo el pretexto de que un específico concepto general como el de Estado de Derecho poseía ya una respuesta predeterminada. Así las cosas, una herramienta jurídica que pretende contradecir formalmente a la ley exigiendo más requisitos que los establecidos por ella, en caso alguno puede deducirse de una idea, que si en algo hay claridad, es que propugna una dignificación de la ley como forma de resolver nuestras disputas sociales.

\subsection{LA INSEGURA SEGURIDAD JURÍDICA}

La seguridad jurídica es enunciada con frecuencia como una de las bases sobre las que descansaría el principio de protección a la confianza legítima ${ }^{43}$. A su turno, se indica que la fuente constitucional de aquel principio sería el art. 19 n 26 de la CPR. Sin embargo, esta conclusión solo tiene su base en el uso explícito -incluso con el ya conocido defecto de redacción de la noma- del concepto de seguridad. Si se observa con detención, la norma solo hace referencia a los límites impuestos a la ley en lo que respecta a su tarea de regulación, limitación o complementación de las garantías constitucionales. La norma, en efecto, establece que esa facultad que posee el legislador en ningún caso podrá afectar la esencia del derecho a regular ni imponer condiciones, tributos o requisitos que impidan el libre ejercicio de aquellos derechos. Como se observará hay una gran diferencia con el contenido que se predica como perteneciente al principio de seguridad jurídica con lo que realmente dispone esta regla.

La idea de "seguridad jurídica", valor de contornos en nada claros, insiste ya sea en una idea de estabilidad en las soluciones dadas por el ordenamiento jurídico o en una idea de repudio a situaciones en que los derechos se encuentren siempre dubitados o no firmes $^{44}$. No obstante, también este tipo de seguridad pretende explicarse mediante criterios tan disímiles como justicia, razonabilidad, proporcionalidad, entre otros. Tal como indica un autor, la seguridad jurídica se conecta "con el «orden», con la "paz», y en general con todos los valores en que se realiza y concreta la «justicia», como son la igualdad, la integridad física y moral, la libertad, la inviolabilidad de domicilio..." 45 .

Los calificativos abundan al momento de tratar de definir lo que significa la seguridad jurídica. "Elemento informador cada vez más imprescindible en la comprensión y funcionamiento del ordenamiento jurídico", "parámetro esencial sobre el que habrá de pivotar la labor del constructor del Derecho..."46 "valor intermedio encaminado a garantizar la consistencia del sistema jurídico ${ }^{47}$, "dogma en que se fundamenta el Estado Liberal

\footnotetext{
43 Sobre el principio de seguridad jurídica y desde diferentes perspectivas, vid. entre mucha bibliografía, PéreZ Luño, A. (1991); Pérez Luño, A. (1992) pp. 273-290; Wojcik Radkowska, C. (2001) p. 195-208. El número 263-264 de la revista Documentación Administrativa del año 2003 estuvo dedicado especialmente al principio de seguridad jurídica y sus manifestaciones.

44 En una formulación ya clásica se suele hacer alusión a la triple dimensión del principio de seguridad jurídica "como conocimiento y certeza del Derecho positivo; como confianza de los ciudadanos en las instituciones públicas y en el orden jurídico en general, en cuanto garantes de la paz social, y, finalmente, como previsibilidad de las consecuencias jurídicas derivadas de las propias acciones o de las conductas de terceros”. Leguina (1987) p. 34.

45 Martínez Roldán (1988) pp. 3352-3353.

46 Castillo Blanco (2002) p. 60.

47 Hierro (1989) p. 198.
} 
burgués ${ }^{48}$, "presupuesto de las libertades y derechos fundamentales" ${ }^{49}$. La claridad en los contenidos, sin embargo escasea. Tanto, que más de alguno ha sostenido que, a diferencia de otros valores o principios del derecho, la seguridad jurídica "no parece tener en sí misma un contenido concreto" 50 .

La fabricación de este interés como principio jurídico no esta exenta de los problemas que más abajo indicaremos. No obstante, además de esas objeciones, cabe mencionar que incluso la premisa mayor de su contenido puede ser negada desde que no siempre es un valor positivo la preservación de una determinada estabilidad o inmovilidad de las situaciones jurídicas. En efecto, bien puede sostenerse que la estabilidad es un valor carente de valoración intrínseca y que depende totalmente de la valoración positiva o negativa de la respectiva situación jurídica que se pretende mantener ${ }^{51}$. No es necesario mirar muy lejos para verificar que la misma instauración de los hoy alabados principios del Estado liberal se han gestado precisamente en escenarios de bajísima estabilidad y en los cuales ha intervenido un afán de reforma y flexibilidad y no un espíritu estático que privilegie los intereses adquiridos de las clases dominantes ${ }^{52}$. Sin embargo, también sería descabellado pensar que una constante movilidad de las situaciones jurídicas será totalmente provechosa ${ }^{53}$. Es profundamente razonable que los intervinientes en cualquier tipo de relaciones exijan cierto grado de predictibilidad en los resultados de ellas. No obstante, en tanto esa predictibilidad debe lidiar junto al legítimo interés de la comunidad de ir modificando sus normas jurídicas para ir avanzando hacia regulaciones más justas y mejores, todo parece indicar que son precisamente las leyes las que deben ir entregando las respuestas de síntesis de aquellos intereses. Tal como ha expresado Castillo Blanco, "la seguridad se encuentra en todo momento en una situación de tensión y equilibrio frente a la justicia expresada en la legalidad concreta" ${ }^{4}$.

Sumar a esta garantía, tal como luego indicaremos, mecanismos de responsabilidad extracontractual cuando se han dañado fuerte y manifiestamente aquellas expectativas legítimas o atenuar los efectos inmediatos de la afectación a la seguridad pueden ser una buena manera de consolidar esa siempre difícil síntesis entre estabilidad y avance.

\section{FABRICANDO PRINCIPIOS}

Por si no fuera poco el efecto de inflación tanto del contenido normativo de la noción de Estado de Derecho como de las mismas normas constitucionales, se ha instalado

\footnotetext{
48 Immordino y Modica (2002) p. 282.

49 Castillo Blanco (2002) p. 35.

50 Castillo Blanco (2002) p. 33.

51 En este sentido véase el siempre agudo análisis de Holmes (2003) pp. 19 y sgtes.

52 Véase Bulliger (1999) pp. 907 y sgtes. La autoridad administrativa más cauta, se sostiene, no puede prevenir los cambios en las políticas públicas. Esas autoridades deben estar en disposición de poder cambiar sus líneas de actuación. Shønberg (2000) p. 11.

53 Podemos coincidir con Castillo Blanco que la Administración Pública se encuentra regida "por la idea fuerza de que es necesaria la certeza jurídica en la configuración de la sociedad para su adecuado desenvolvimiento" de forma tal que se trate de dotar "a las relaciones interprivatos, o a aquellas que se generan entre la Administración y los particulares de la necesaria certidumbre y certeza en su configuración”. Castillo Blanco (2002) p. 26.

54 Castillo Blanco (2002) p. 62.
} 
también en el último tiempo una especie de fábrica de principios cuyo objetivo primordial es la solución de casos concretos mediante una norma a la medida de la solución a la que se quiere deliberadamente arribar. Si lo se quiere previamente es disminuir los efectos de una norma administrativa nada mejor que considerar como instalado en el ordenamiento jurídico un principio "pro administrado" o uno de "primacía de la persona humana" que hace que una norma administrativa pueda ser interpretada de manera restrictiva ${ }^{55}$.

Tal como indica Comanducci, la resolución de casos en base a principios ayuda "a los jueces a encontrar siempre una justificación ex post para sus propias decisiones, pero parece no reducir, sino aumentar la indeterminación ex ante del derecho" 56 .

Este continuo proceso de fabricación de principios tiene desde luego diversos inconvenientes. Algunos de ellos son los siguientes.

Tal vez uno de los grandes problemas que presenta la construcción de principios es que normalmente se estructuran sobre la base de expresiones retóricas que todos podríamos compartir. ¿Quién en verdad no estaría de acuerdo en que en todo tipo de relaciones debe primar siempre la persona humana o la buena fe o la seguridad jurídica? Estos acuerdos tan generales y tan compartidos, sin embargo, normalmente esconden oscuras falacias.

Por un lado, es difícil tratar de buscar cuál es la innovación que un principio como todos estos produce. Por ejemplo, en un mundo jurídico hecho de humanos y para humanos hacer primar la persona humana es algo claramente circular. En efecto, la totalidad de problemas que nos presenta la vida constituyen siempre conflictos "entre humanos" por lo que hacer primar las posiciones jurídicas de todas las personas no construye solución alguna. Por otro lado, y como sucede con muchos principios jurídicos, el principio de primacía de la persona posee un contenido extremadamente indeterminado. ¿Qué persona es la que debe primar? Es lo que debemos preguntarnos inmediatamente. Supóngase que nos encontramos ante un problema de extensión de la potestad sancionadora de la Administración. Un negocio de venta de comida que se pretende clausurar por razones sanitarias. Pues bien, la "persona que debe primar" ¿es el dueño del local comercial o, por el contrario, es el universo de los posibles consumidores? En un caso de extensión de potestades regulatorias de fijación de las tarifas telefónicas, la persona humana que debe primar ¿son los dueños de las acciones de la compañía o el universo de consumidores de servicios telefónicos? Si pretendemos la aplicación judicial de este principio, lamentablemente la persona humana solo será el propietario y los accionistas de la empresa, pues entre ellos y el Estado será el juicio

55 Diversas reflexiones críticas sobre el auge de los principios jurídicos, véase Carbonell, Letelier y Coloma (2011). Sobre la introducción de principios jurídicos en la modulación de efectos invalidatorios, véase LETELIER (2011) pp. 356 y sgtes.

56 Y ello por tres tipos de razones: “1) porque una de las características más comunes de las normas que están configuradas como principios es la mayor vaguedad respecto a las otras normas, y por tanto esta característica aumenta en vez de reducir la indeterminación ex ante; 2) porque, en consecuencia, la creación y configuración de principios, a falta de una moral común, aumenta la discrecionalidad de los jueces, que pueden decidir los casos haciendo referencia a las propias, subjetivas, concepciones de la justicia, y también esto, naturalmente, aumenta la indeterminación ex ante; 3) porque la peculiar manera de aplicar las normas configuradas como principios, o sea la ponderación de los principios caso por caso, a falta de una jerarquía estable y general entre los principios, aumenta también ella la discrecionalidad de los jueces y la indeterminación ex ante del derecho". Comanducci (2005) pp. 92-93. 
de impugnación de la sanción de clausura o del acto administrativo de fijación tarifaria ${ }^{57}$. El universo de consumidores y de usuarios de telefonía, en cambio, no participará en aquel juicio, salvo que entendamos que es el propio Estado el que vela por los intereses de esas personas, o de otro modo, que en el análisis de la impugnación esas personas deben primar tanto como los otros. Desde esa perspectiva, la acción estatal es también una forma por la cual se protege aquella primacía.

Pues bien, cosa parecida ha sucedido con la confianza legítima. Desde luego, podemos siempre discutir que allí donde la Constitución dice una cosa se entiende incluida esta protección a la confianza legítima. De ello ya se ha hablado en el acápite anterior. Sin embargo, no me parece que resulte tan difícil asumir que ni la seguridad jurídica, ni la buena fe, ni la confianza legítima tienen una consagración constitucional ${ }^{58}$. Otros países, por ejemplo, han protegido expresamente a nivel constitucional la seguridad jurídica. España, lo ha hecho en el art. 9.3 de su Constitución.

Por el contrario, lo que normalmente se hace para "producir" este tipo de principios es seguir un proceso inductivo, esto es, se observan diversas normas expresas del sistema jurídico infraconstitucional y se busca la ratio que resulta común en todas esas normas ${ }^{59}$ para luego alzar esa ratio común como principio. Este proceso, sin embargo, presenta dos graves problemas.

\subsection{El PROBlema del SeSGo de Selección}

Un primer problema en la construcción inductiva de este tipo de principios es que no se encuentra claramente justificado el que un cúmulo de razones comunes pueda luego servir como razón de otro tipo de situaciones. Veamos un ejemplo que puede clarificar esta objeción. El proceso de construcción del principio de buena fe -pieza angular en el edificio de la confianza legítima- podría realizarse de la siguiente forma: En primer lugar se toman diversas normas que protegen la buena fe. En este sentido el Código Civil es rico en la protección de este interés. En materia de restituciones se protege al que se encuentra de buena fe (arts. 94, 189, 327, 900, 907, 1267, 1853, 2302), o se le otorga validez a actos cuando el que lo celebra está de buena fe (art. 122) o se protege a personas externas a una relación jurídica mientras ellas estén de buena fe (arts. 221, 1337, 1490), se otorgan derechos a los que están de buena fe (arts. 646, 702, 1814, 1916) o simplemente se presume la buena fe sin que ello comporte una especial protección jurídica (art. 707). Encontradas estas normas que protegen la buena fe de las personas entregándoles diversas consecuencias positivas a

\footnotetext{
57 Esto revela los problemas que tiene la resolución de problemas de alto impacto en políticas públicas a través de procesos judiciales cerrados a las partes y en los que prima una relación de mero reconocimiento de derechos objetivos.

58 Véase Ferrada (2007) p. 143.

59 Sobre las dificultades que tiene el procedimiento inductivo en orden a ser hábil para producir una transferencia de validez desde una norma determinada en dirección a la norma que se induce, véase IgARTúa (1986) pp. 36 y sgtes.
} 
sus actuaciones "inducimos" que todas esas normas son manifestación de un interés que al ordenamiento jurídico -o a las personas que lo crean- le interesa proteger ${ }^{60}$.

Sin embargo, no es para nada claro que un determinado conflicto pueda ser resuelto simplemente por la aplicación de la idea de la buena fe. Así, por ejemplo, imagine que se ha ordenado restituir a un poseedor un bien inmueble a su verdadero dueño y el primero le ha hecho mejoras a ese bien. ¿Debe el dueño restituir las mejoras voluptuarias realizadas como los hermosos jardines que mandó construir? Nuestro Código Civil resuelve este problema de manera expresa en el art. 911 determinando que el poseedor de buena fe está en la misma posición que el de mala fe. Ello es así, porque en esta norma no es la buena fe un interés que agote el conjunto de valores o bienes que pretende ser custodiados por el derecho.

Pero no solo sucede que ante una realidad compleja el hecho que un interés rija en algunas situaciones no implica necesariamente que deba regir para otras sino que es el proceso de construcción del principio el que está también viciado.

Pongamos un ejemplo y participemos nosotros en esta fábrica de principios. El art. 172 del CC permite al cónyuge inocente en un divorcio revocar las donaciones que le hubiere hecho al cónyuge culpable de adulterio. Por su parte, el art. 324 del CC autoriza a dejar de dar alimentos al que injurie al alimentante, mientras que el art. 1208 permite el desheradamiento de un legitimario cuando este hubiere cometido injuria atroz contra el causante. El art. 11 del Código Penal califica como atenuante "la de haberse ejecutado el hecho en vindicación próxima de una ofensa grave causada al autor". Pues bien, de estas normas, podría inducirse un "principio de venganza" mediante el cual es posible obtener beneficios o una posición privilegiada o mejorada cada vez que un actor ejecute una conducta como reacción negativa frente a otra. Podríamos hasta coincidir que este principio pueda tener vigencia en nuestro derecho, pero en lo que de seguro no coincidiríamos es que en todos los casos concretos en que se dé una situación similar cobrará vigencia este supuesto principio. Mal que mal una recolección de normas tendrá siempre la objeción metodológica de que tal vez el hecho de haberse regulado expresamente una situación es precisamente por el hecho de que la misma regla no se aplica en otros casos.

\subsection{EL PROBLEMA DEL EFECTO DEL PRINCIPIO}

En el presente caso el ejercicio inductivo realizado para la fabricación del principio de confianza legítima pretende un objeto bastante inmediato y que no es otro que el de limitar la norma del art. 53 de la LBPA. Así, si la referida norma puede ser aplicada a un universo de casos lo que se pretende con la aplicación del principio de confianza legítima es precisamente disminuir ese conjunto de casos. Este resultado, sin embargo, no puede ser obtenido sin violar las reglas sobre las que se construye el sistema de fuentes jurídicas.

En efecto, si el referido principio ha sido inducido por un cúmulo de razones comunes extraídas de diversas normas legales, esa ratio común, no puede en caso alguno produ-

\footnotetext{
${ }_{60}$ Es lo que hace la CGR cuando sostiene que "las infracciones al principio de juridicidad no siempre anulan el acto irregular, pues esa sanción no puede afectar a los terceros de buena fe que actuaron con el convencimiento que el acto administrativo se ajustaba a Derecho, encontrándose amparados por la presunción de buena fe del artículo 707 del Código Civil en tanto no se pruebe lo contrario". Dictamen 12.272 de 2002. Para comentarios a esta línea jurisprudencial, véase BoetTiger (2009) pp. 311 y sgtes.
} 
cir el efecto de delimitar el ámbito de otra norma legal mucho más específica que aquellas que han motivado la inducción e incluso dictada con posterioridad a ellas. Esto afectaría las reglas de solución de antinomias que el sistema jurídico posee, toda vez que se estarían usando normas legales para limitar otras normas legales mucho más específicas. En verdad, lo que suele hacerse en estos casos es tratar de subir de nivel jerárquico a aquellas razones comunes. Es decir, aun cuando ellas se encuentran en leyes, mediante un proceso no bien transparentado se pretende que la ratio común inducida de ellas valga más que las propias fuentes. Es casi como una labor de constitucionalizar aquellas características comunes. Una vez hecho este upgrade, puede entonces aplicarse el principio recién fabricado como forma de reducir el campo normativo de otras leyes. Como puede verse este proceso pretende burlar, bajo el manto de las generalizaciones, la misma jeraquización de las fuentes normativas.

\section{LA LEGALIDAD ENTREGADA A LA BUENA FE}

Finalmente, además de las referidas críticas a los fundamentos de la construcción del principio de confianza legítima como límite a la potestad invalidatoria, existen otras buenas razones para rechazarlo. Todas ellas giran en torno a la inconveniencia de dejar entregada la legalidad a un estado psicológico subjetivo como la buena fe. Y ello por varias razones:

\subsection{Afectación de la igualdad ante la ley}

La protección a la confianza legítima altera el principio de igualdad ante la ley y destruye el argumento de tertius comparationis como forma de requerir de la Administración una conducta coherente e igualitaria ${ }^{61}$. En efecto, la observación de los tratos discriminatorios y arbitrarios que pueda tener la Administración con los ciudadanos se percibe principalmente comparando las respuestas que ella da en iguales situaciones a diversos sujetos. Percibidas estas respuestas diferenciadas pueden incoarse rápidamente los mecanismos de ajuste ya sea cuestionando la legalidad o la razonabilidad de esos tratos disímiles.

Dejar, en cambio, la coherencia del ordenamiento a la generación subjetiva de confianzas en la supuesta estabilidad del ordenamiento jurídico puede legitimar tratamientos jurídicos diversos ante situaciones idénticas trastornando las posibilidades de las personas de reclamar la igualdad jurídica trayendo a colación formas de trato que se le han dado en casos iguales a los suyos. La idea de confianza legítima imposibilita este tipo de argumentaciones que tanta riqueza provee al examen de la legalidad o la razonabilidad en todo el derecho solidificando situaciones contrarias al ordenamiento jurídico.

Someter la legalidad a la buena fe puede construir órdenes jurídicos paralelos provocando atentados graves a la misma igualdad ante la ley. Por otra parte, no es precisamente la mantención de situaciones ilegales lo que puede portar seguridad jurídica a las decisiones institucionales sino que es su ajuste a un parámetro más o menos conocido, como la ley, lo que entrega mayores dosis de predecibilidad y seguridad a los ciudadanos respecto de las

\footnotetext{
${ }_{61}$ Sobre el argumento de tertium comparationis como forma de hacer efectiva la igualdad en la aplicación del derecho y la razonabilidad de toda decisión jurídica véase Morrone (2001) pp. 79 y sgtes. Sobre los deberes de coherencia administrativa, véase Medina (2006) pp. 282 y sgtes.
} 
decisiones que sus autoridades adopten ${ }^{62}$. La confianza legítima, al contrario, produce seguridad solo en el individuo beneficiado y no a nivel de sistema jurídico.

Suele indicarse, sin embargo, que la confianza legítima genera seguridad de que las decisiones administrativas no se miren como sujetas a examen o con vicios de legalidad latentes. Esta seguridad es, no obstante, ficticia. Una vez adoptada la decisión social de someter a la actividad jurídica administrativa a fuertes controles jurisdiccionales, la única seguridad que puede lograrse en términos de estabilidad de esos actos es aquella que deriva de los plazos de caducidad de las acciones contencioso administrativas ${ }^{63}$. Y en este sentido, el plazo de dos años de la potestad invalidatoria cumple el mismo rol.

\subsection{MASificación de la BUENA Fe}

La protección a la confianza legítima introduce una variable en extremo indeterminada en el análisis jurídico. En efecto, en sociedades como la nuestra, reconocidas por una corrupción bastante acotada, es dable pensar que por lo general las personas (tanto Administración como ciudadanos) se desenvuelven en sus relaciones jurídicas con un comportamiento correcto y de buena $\mathrm{fe}^{64}$. Suponer que en todos los casos donde las partes se han comportado de forma correcta son, a su vez, casos que ameritan la protección de confianzas limitaría considerablemente la potestad invalidatoria y supondría reducir este instituto solo a casos de fraudes o malversaciones, lo que claramente no fue la intención del legislador democrático.

Por otro lado, si las confianzas singulares se van solidificando con el tiempo hasta transformarse en confianzas legítimas, es decir, si el problema del surgimiento de una confianza legítima es una cuestión temporal acerca de su mantención, la protección de la confianza legítima podría tener aplicación (como en efecto la tiene) en aquellos ordenamientos donde no existe plazo alguno para ejercerla -aunque esto siempre pueda ser discutible- pero no en nuestro contexto donde el plazo de dos años parece ser un lapso bastante razonable como para proteger aquella estabilidad del ordenamiento jurídico al menos impidiéndole a la Administración dejar sin efecto sus propios actos, obligándole a recurrir a los tribunales si quisiese perseguir aquella declaración pasado ese término ${ }^{65}$. De ahí que el propio Bermúdez reconozca que este plazo de dos años viene a proteger "al principio de seguridad jurídica, que se estima en la base de todo Estado de Derecho"66.

\subsection{MeCANismo ineficiente}

Plazos para la invalidación, imposibilidad de retroactividad y responsabilidad son algunos de los mecanismos que han ido rodeando a la invalidación como forma de atenuar los

\footnotetext{
${ }^{62}$ En este sentido, véase García Luengo (2002) p. 197 y sgtes.

63 En este sentido, CMET con Min. de Transportes y Telecomunicaciones (2012).

${ }^{64}$ En el Corruption Perceptions Index de 2012 (Transparency Internacional), Chile ocupa el lugar número 20 al lado de países como EEUU y Uruguay. Véase este informe en linea: http://cpi.transparency.org/cpi2012/ results/ (consultado el 9 de julio de 2013).

${ }^{65}$ Y no generando un juicio en que la Administración se demande a sí misma sino que un juicio en que su contraparte sea el o los beneficiados por el acto. Véase Letelier (2002) p. 711 y sgtes.

66 Bermúdez (2005) p. 96.
} 
efectos perjudiciales que efectivamente pueden producirse en las confianzas legítimas de los ciudadanos. En materia de plazos, por ejemplo, se ha preferido en Francia una regla general de invalidación pero sujeta a plazos incluso más largos que el disponible en nuestro país.

En la UE, por su parte, existe una regla de que las decisiones ilegales son siempre prospectivamente invalidables y no existe límite para ello ${ }^{67}$. La Administración puede siempre eliminarlas pero pro futuro. En ese mismo sentido, existen limitaciones para las revocaciones con efectos retroactivos. Una de ellas es que la revocación se haga en un periodo razonable o que haya un importante interés para mantener la norma ilegal ${ }^{68}$. En la búsqueda de ese interés se toma especialmente en cuenta el escenario general de ella, por ejemplo, si la mantención del acto ilegal genera una distorsión en la competencia o entrega beneficios desiguales ${ }^{69}$.

La audiencia de la parte afectada es también otra garantía procedimental y ella ha ido consolidándose de forma rápida ${ }^{70}$. De hecho en nuestro entorno, se han dejado varias veces $\sin$ efecto invalidaciones por faltar la referida audiencia ${ }^{71}$.

Este tipo de mecanismos optimiza tanto la necesidad de depuración del sistema jurídico como la protección de las confianzas legítimas de los ciudadanos, toda vez que garantiza condiciones objetivas de procedimiento que permiten -cual criterio de proporcionalidad- atender a ambos bienes sin desmejorar la posición de cada uno de los intereses en conflicto.

\subsection{Produce importantes PRoblemas en los mercados}

La explicación más primitiva de las regulaciones estatales ve la inclusión de requisitos legales como cargas que generan aumentos de costos, disminución en la producción y pérdida de eficiencia. Si bien el desarrollo de la economía ha mostrado la falta de veracidad de esta premisa, en términos generales representa un análisis teórico que explica la incidencia de una regulación estatal con efectos generales en el mercado. Los requisitos legales, al imponer cargas, normalmente encarecen los productos. Ello, sin embargo, no debe necesariamente verse negativamente toda vez que estos requisitos, cuando están bien planteados, traspasan riqueza a otros, distribuyen externalidades o mejoran las condiciones de mercado al largo plazo.

\footnotetext{
67 Véase C 7/56 y 3-7/57 Algera v. Common Assembly [1957] ECR 39; C 159/82 Verli-Wallace v. Commission [1983] ECR 2711.

${ }_{68}$ Véase T-336/94 Efisol v. Commission [1996] ECR II-1343.

69 El leading case en esta materia es C 14/61 Hoogovens v. High Authority [1962] ECR 253.

70 Véase Hlophe (1990) p. 201 y sgtes. Esta era por lo menos la fisionomía del principio en sus primeros años de vida en UK. Véase Schmidt v. Home Secretary (1969) 2 Ch. 149.

${ }^{71}$ Situación que refleja la precaria capacitación jurídica que han tenido los funcionarios que les ha tocado implementar por primera vez la ley 19.880 .

Reconociendo la importancia del requisito, la Corte Suprema ha sostenido que la ley 19.880 "ha establecido como trámite necesario para invalidar un acto administrativo el requisito de la audiencia previa, con lo cual materializa el principio constitucional del justo y racional procedimiento contemplado en el numeral $3^{\circ}$ del artículo 19 de la Carta Fundamental, de forma que confiere a los interesados o afectados una oportunidad para que expongan sus argumentos en el procedimiento invalidatorio". Vásquez con I. Municipalidad de Osorno (2013).
} 
Pues bien, en este tipo de escenarios, es vital para el funcionamiento del mercado que los requisitos legales estén distribuidos de manera igualitaria en todos los participantes de un mismo sector. Cualquier diferencia en esas imposiciones genera la posibilidad de que el beneficiado por ellas pueda incorporarlas en el precio de tal forma que la diferencia de regulaciones se transforme en un elemento que incide directamente en ese mercado. Una regulación diferenciada entonces provoca una alteración que atenta contra la libre competencia.

Pues bien, sostener actos ilegales respecto de algunos por el hecho de estar ellos de buena fe y aplicar respecto de otros una regulación legal distinta puede generar aquellos problemas en las reglas de mercado ${ }^{72}$. La permanencia de la ilegalidad puede mejorar la posición en el mercado de un productor, pues la diferencia en los precios en competencia se explica únicamente por aquella diferente regulación y no por las condiciones o características específicas de un producto. La elección de ese bien por parte de los consumidores, entonces, deriva simplemente de la buena fe del mismo beneficiario.

Una situación de este tipo no debiese ser tolerada. La regulación jurídica no debe producir desigualdades en la competencia sino que debe ser impuesta de manera igualitaria a todas las personas. Las cargas deben ser distribuidas de manera equitativa para que así no se generen discriminaciones ilegales. Solo de esta forma se cumple el mandato de prohibición de discriminación arbitraria en materia económica establecido en el art. 19. $\mathrm{N}^{\circ} 22$ de la CPR y el de igual repartición de las cargas públicas establecida en el art. $19 \mathrm{~N}^{\circ} 20$ de la misma carta.

Así las cosas, en tanto la protección del acto ilegal puede distorsionar gravemente la competencia, debe buscarse una forma diversa de proteger aquellas confianzas para así recomponer los perjuicios originados por su violación sin alterar las condiciones de mercado. Si lo que se quiere es resguardar eficientemente el actuar legal de la Administración y no producir aquella distorsión, la mantención de ilegalidades parece ser un interés mucho más débil que el restablecimiento ${ }^{73}$.

\subsection{LA ELIMINACIÓN DE LA NORMA ES EL EFECTO ESENCIAL DE LA INVALIDACIÓN}

Los requisitos de plazo y audiencia constituyen la regulación de la potestad invalidatoria. En este sentido, es perfectamente posible plazos distintos o fórmulas diversas de notificación. Audiencia previa y dos años son simplemente opciones regulatorias realizadas por el Legislador. La protección a la confianza legítima, por el contrario, elimina por completo la invalidación. Ella es su propia negación toda vez que el efecto jurídico básico de la potestad es precisamente expurgar el referido acto.

Por la misma razón tampoco parece razonable que la teoría de los actos propios pueda servir como justificación a la limitación de las competencias invalidatorias. La figura de la invalidación ha superado el argumento de los actos propios pues ella procede precisamente contra actos emanados de la Administración, lo que hace ilógico que sea ese mismo hecho el que delimita aquella invalidación. "Claro está -indica Rebollo Puig- que en la mayoría de los casos los vicios de los actos administrativos son exclusivamente debidos a

\footnotetext{
72 Sobre esta extensión en los efectos del acto administrativo invalidado, véase FERRADA (2007) p. 144.

73 Shønberg (2000) p. 14.
} 
la propia Administración y que si la Administración puede revisar de oficio sus actos nulos e impugnar ante la jurisdicción contencioso-administrativa sus actos anulables es porque puede alegar los motivos de invalidez que ella mismo originó" 74 . Si se quiere poner de otra forma, esta es una excepción a la teoría de los actos propios como forma de asegurar la mantención de actos jurídicos ilegales.

La misma lógica permite descartar el argumento que afirma que si la CGR tomó antes razón del acto administrativo ello imposibilitaría invalidar el acto con posterioridad. Una conclusión de este tipo privaría al órgano administrativo de una potestad que le ha entregado expresamente la ley y cuyo núcleo básico es precisamente realizar un examen de legalidad ex post a la dictación del acto administrativo. Por otra parte, un argumento de este tipo limitaría la invalidación solo a los casos en que la CGR no ha tomado razón, evento, que por lo demás, depende de la misma CGR al ser ella misma la que, racionalizando sus recursos económicos, determina qué actos están o no sujetos a esa revisión ${ }^{75}$.

Finalmente, aquella restricción es rechazada incluso por la propia Contraloría cuando sostiene que una vez que se ha tomado razón de un acto, aquella declaración de legalidad no puede ser dejada sin efecto por la misma CGR. Sin embargo -indica el órgano contralor- una vez que se ha cumplido el trámite de toma de razón, corresponde a la propia autoridad administrativa y no a la Contraloría General invalidar la medida que pudiere adolecer de un vicio de ilegalidad ${ }^{76}$.

\section{RESPONSABILIDAD EXTRACONTRACTUAL E INVALIDACIÓN DIFERIDA. DOS MEDIOS PARA PROTEGER CONFIANZAS LEGÍTIMAS Y SEGURIDAD JURÍDICA}

La idea de proteger las confianzas legítimas no es, a pesar de todas las razones esgrimidas en este trabajo, una idea incorrecta. El argumento de la confianza legítima, por el contrario, contiene una idea acertada o, más bien, un interés bastante digno de proteger. Este podría ser explicitado en los siguientes términos. Siendo el administrado un receptor de las normas generadas por la Administración es razonable que él dirija su actuación entendiendo que dichas normas son legales y que lo seguirán siendo mientras dicho acto se encuentre vigente. Desde otra perspectiva, es también razonable que futuras estimaciones institucionales acerca de la ilegalidad de ese acto no le originen perjuicios a quien no ha podido ni ha debido prever la ilegalidad ${ }^{77}$. Si el administrado se encontraba de buena fe no debería sufrir perjuicio alguno con el actuar ilegal de la Administración.

Sin embargo, mientras algunos piensan que este tipo de intereses que parece necesario proteger conlleva una suerte de imperativo de que "las relaciones jurídico-administrativas que han nacido producto de dicha intervención deben ser mantenidas mientras no

\footnotetext{
74 Rebollo Puig (2002) pp. 213 y sgtes.

75 Voluntad que concretizó en la Res. 1600 de 2008.

76 Dictamen $\mathrm{N}^{\circ} 57.558$ de 2012. En el mismo sentido, dictámenes $\mathrm{N}^{\circ}$ s. 30.117 de 1993, 25.768 de 1995 , 11.724 de 2004 y 11.733 de 2009

77 Sobre la idea de estimaciones institucionales de validez, véase LeTELIER (2011) p. 268.
} 
exista un cambio de circunstancias"78, otros pensamos, por las razones ya indicadas en este texto, que aquella defraudación de las confianzas debe ser abordada de una forma diversa. En este sentido, la responsabilidad extracontractual del Estado es una forma eficiente de protección a las referidas confianzas.

La principal virtud de proteger estas confianzas mediante un mecanismo como la responsabilidad es que esta es una respuesta restringida (en el sentido que afecta a un sujeto, al que se indemniza) para un problema individual (la disposición sicológica de la buena fe por parte del ciudadano). Por el contrario, la limitación invalidatoria es una respuesta general (en el sentido que afecta al sistema jurídico en su totalidad) para el mismo problema individual. Si lo que se tiene es un problema puntual deben entonces pensarse respuestas que ataquen ese problema puntual y no generar respuestas que afectan a otros sujetos generando a su vez problemas consecuentes.

Así las cosas, dos supuestos indemnizatorios pueden darse en este escenario:

\subsection{Daños causados por la defraudación de confianzas legítimas depositadas EN EL ACTO QUE LUEGO ES LEGALMENTE INVALIDADO POR CAUSA DE ILEGALIDAD ${ }^{79}$ \\ En este caso, la invalidación constituye una constatación administrativa institucional} de la ilegalidad. Es la ilegalidad en que incurre la administración la que hace que el ciudadano realice inversiones o confíe en la mantención del acto. La caída de esas inversiones y los daños originados por ello deben ser indemnizados. El fundamento indemnizatorio no puede ser otro que el de la ilegalidad. Se ha dicho que lo que "realmente" produce el daño es el acto administrativo de invalidación -acto a la sazón legal- y no el acto ilegal primigenio. En efecto, si se estima que es el acto invalidatorio es el que defrauda la confianza, parece lógico que se considere que es este el causante de los daños ${ }^{80}$. Esto, sin embargo, no me parece correcto. Los daños se radican en bienes o posiciones concedidas por el acto ilegal. Es la ilegalidad, declarada institucionalmente en un momento posterior, la que defrauda al ciudadano y lo daña toda vez que este tenía buenas razones para pensar que la autoridad actuaba conforme a derecho. El acto causante del daño es, entonces, el acto ilegal y no la legal invalidación. Por lo demás si se piensa en términos disuasivos, la obligación indemnizatoria pretende reconducir a la Administración no a que en situaciones posteriores no invalide sino a que produzca en el futuro actos legales.

El incumplimiento de la legalidad es la mayoría de las veces coincidente con la falta de servicio toda vez que actuar legalmente es parte del estándar básico que se le exige a todo servicio público ${ }^{81}$. En algunos casos excepcionales, sin embargo, la ilegalidad podrá apartarse de la falta de servicio cuando el órgano público actúa de la manera esperable, esto es, sin falta de servicio, pero es la definición institucional de esa legalidad la que construye

\footnotetext{
78 BERMÚdez (2005) p. 102.

79 En verdad, los daños no se originan en la confianza legítima sino en bienes e intereses que estaban respaldados en la confianza acerca de la legalidad del acto que hizo posibles aquellas obtenciones de bienes e intereses.

${ }^{80}$ Véase Medina (2006) p. 290 y sgtes.

${ }^{81}$ Sobre la ilegalidad como fundamento de la responsabilidad patrimonial, véase Medina (2005) pp. 253 y sgtes.
} 
la ilegalidad de una forma no esperable. Un clásico ejemplo de esto se presenta cuando el tribunal o el órgano contralor se aparta de sus anteriores precedentes reformando la legalidad que hasta ese momento estaba vigente y a la cual se sujetó el servicio público. Así, si bien ha habido una declaración institucional de ilegalidad, el servicio público no ha podido de manera alguna, comportarse de una manera diversa ${ }^{82}$. Además de estos casos, debe descartarse la responsabilidad cuando la invalidación ha eliminado una norma en cuya ilegalidad el administrado ha participado o no ha podido sino conocer claramente. La eliminación de la responsabilidad en estos casos es bastante pacífica ${ }^{83}$.

\subsection{DAÑOS CAUSADOS POR LA INVALIDACIÓN ILEGAL DE UN ACTO ADMINISTRATIVO} PERFECTAMENTE LEGAL

En este supuesto, es la ilegalidad de la invalidación, declarada institucionalmente, la que origina daños en el particular cuando los derechos o privilegios obtenidos por el acto invalidado son suspendidos por la invalidación generándose con ello perjuicios económicos posibles de cuantificar. En este tipo de casos, la rápida resolución del "juicio breve y sumario" establecido en el art. 53 inc. $3^{\circ}$ de la LBPA en el cual se impugna la invalidación administrativa es una buena forma de atenuar los daños en el administrado, restringiendo así los perjuicios a ser indemnizados por parte de la Administración. Este supuesto no presenta características especiales siguiendo la lógica de la responsabilidad por actos ilícitos de la Administración.

Finalmente, si bien la principal forma de proteger un bien jurídico como la seguridad jurídica es la existencia de un plazo de dos años de caducidad de la potestad invalidatoria $^{84}$, creo también posible incluir otra herramienta para lograr el mismo objetivo: la invalidación diferida o planificada. Este tipo de invalidación supone la decisión administrativa

\footnotetext{
82 Véase Ferrada (2012) pp. 294 y sgtes. En el mismo sentido, Agrícola y Comercial Las Araucarias Limitada con I. Municipalidad de San Esteban (2013) de 16 de mayo de 2013. En contra, Díez (2012) pp. 220 y sgtes. Una de las primeras premisas que debe incorporarse en el razonamiento que justifica indemnizaciones en casos de actuaciones jurídicas de la Administración es que este es un buen sistema para evitar actuaciones ilegales y que con él se construye un buen sistema de reparto de derechos y cargas entre ciudadanos y colectividad. Esta premisa, sin embargo, no ha sido generalmente compartida. En UK, por ejemplo, la perspectiva adoptada por los tribunales es justamente la contraria, esto es, que el hecho que un tribunal anule una decisión administrativa no genera prima facie derecho a ser indemnizado. Razones de sistema, de costos de transacción procesales, de falta de herramientas de los tribunales en la fijación de los estándares respecto de decisiones administrativas complejas, entre otras razones, han justificado esta perspectiva. Véase Dorset Yatch Co vs. Home Office [1970] AC 1004; Hill vs. Chief Constable of West Yorkshire [1989] AC 53, entre otras.

83 En tanto elimina la defraudación de la buena fe como justificación del comportamiento del administrado. Véase por todos, Medina (2005) pp. 344 y sgtes.

${ }^{84}$ La CGR ha abierto, no obstante, una vía para desconocer ese plazo de dos años. Si en uso de su potestad dictaminante detecta una ilegalidad puede ordenarle al órgano administrativo invalidar y dicho órgano no puede resistirse a cumplir el dictamen bajo el pretexto de haberse cumplido ya el plazo de dos años. Así lo ha indicado en el Dictamen 46719 de 2013 indicando que tal como lo sostuvo en sus Dictámenes $N^{\text {os }} 62.378$ de 2009 y 24.258 de 2010 "la obligatoriedad de sus pronunciamientos es pura y simple, sin que proceda someterla a plazo o condición alguna”. La mantención jurídica de este criterio solo puede explicarse por el beneficio directo para el ciudadano que se producía en los casos en que esos dictámenes se dictan. Sin embargo, bastará que la invalidación sea perjudicial para el ciudadano para que este criterio deba necesariamente variar pues él atenta contra la seguridad jurídica garantizada por el referido plazo de dos años.
} 
de invalidar un acto administrativo pero programando sus efectos invalidatorios en plazos diversos a los del acto administrativo. Una invalidación de este tipo le permite al afectado recibir el acto invalidatorio de una forma menos disruptiva de sus confianzas legítimas reduciendo considerablemente sus daños y obligándole a ajustar su conducta a la legalidad de una manera gradual o en un periodo razonable de tiempo.

Esta invalidación diferida debe ser cuidadosamente decretada toda vez que, tal como hemos referido, la mantención del acto puede originar problemas mucho mayores que su inmediata eliminación. Sin embargo, en muchos otros casos los efectos de la mantención del acto respecto de terceros pueden ser menores, aconsejándose entonces utilizar una planificación invalidatoria.

La justificación normativa del uso de una potestad de este tipo puede encontrase en diversas reglas. En efecto, si bien el art. 51 inc. $3^{\circ}$ establece que los actos administrativos producen efectos desde su notificación o publicación, nada obsta a que dichos actos puedan estar sujetos a plazo o condiciones. Dichos elementos son fijados de forma inmediata en el acto administrativo quedando su ejecutividad supeditada al cumplimiento del plazo o de las condiciones ${ }^{85}$.

Por otra parte, la disposición temporal de los efectos de actos administrativos no es ajena al Derecho Administrativo. Así, aun ante plazos legales, la Administración puede siempre, de conformidad al art. 26 de la LPA, conceder ampliaciones de plazo a los interesados si las circunstancias así lo aconsejan.

En este mismo sentido, el hecho que la Administración tenga un plazo de dos años para realizar la invalidación expresa una obligación que puede ser ejercida discrecionalmente dentro de ese plazo. La Administración puede estudiar por todo ese tiempo el ejercicio de la potestad invalidatoria lo que le otorga un espacio temporal del que puede disponer. Ello posibilita que pueda concederle al Administrado un tiempo prudente para que ajuste su actuar a la legalidad luego de practicada la invalidación.

Por otra parte, la norma del art. 52 de la LBPA establece una prohibición de retroactividad de los actos administrativos, prohibición que se levanta cuando el acto es favorable al administrado. Dicha norma contiene una regla que permite que los efectos de un acto lícito sean eliminados por otro acto lícito que se dicta con posterioridad. Esta misma regla de afectación es la que se aplica cuando se difiere o programa una invalidación toda vez que, en tanto favorable para el administrado, se permite que desde la fijación del plazo haya una afectación prospectiva o retroactiva en los efectos del acto administrativo invalidatorio. Ello permite que pueda haber una entrada diferida de todos los efectos de la invalidación o una entrada por etapas de la misma.

El hecho de que estemos en presencia de una ilegalidad no permite llegar a un resultado diferente. La disposición de plazos discrecionales puede verse incluso en presencia de actos ilegales como se indica en el art. 56 de la LBPA. Dicha norma entrega a la Administración la facultad de fijar discrecionalmente plazos para la corrección de vicios procedimentales, esto es, para corregir las ilegalidades cometidas al interior del procedimiento administrativo.

85 BERMÚdeZ (2011) p. 116. 
Así las cosas, la Administración puede, al momento de dictar el acto invalidatorio sujetar sus efectos a plazos posteriores o programar los efectos de la invalidación en etapas o fechas determinadas. Todo ello en favor del administrado para así atenuar los perjuicios ocasionados por la ilegalidad cometida.

\section{BIBLIOGRAFÍA}

Bermúdez, Jorge (2005): "El principio de confianza legítima en la actuación de la Administración como límite a la potestad invalidatoria”, en: Revista de Derecho, Universidad Austral de Chile, Vol. 18, No 2: p. 83-105.

Bermúdez, Jorge (2011): Derecho Administrativo General (Santiago, LegalPublishing, segunda edición).

Bingham, Tom (2010): The Rule of Law (London, Penguin) 213 pp.

Blanke, Hermann-Josef (2000): Vertrauensschutz im deutschen und europäischen Verwaltungsrecht (Tübingen, Mohr Siebeck) 610 pp.

Boettiger, Camila (2009): "El principio de la buena fe en la jurisprudencia de la Contraloría General de la República en materia urbanística”, en: Actualidad Jurídica, $\mathrm{N}^{\circ} 19$ : pp. 309-326.

Buldinger, Martin (1999): "Vertrauensschutz im deutschen Verwaltungsrecht in historisch-kritischer Sicht", en Juristenzeitung: pp. 905-913.

Carbonell, Flavia; Letelier, Raúl y Coloma, Rodrigo (edits.) (2011): Principios Jurídicos. Análisis y critica (Santiago, Thomson Reuters) 356 pp.

Castillo Blanco, Federico (1998): La Protección de Confianza en el Derecho Administrativo (Madrid, Marcial Pons) $381 \mathrm{pp}$.

Castillo Blanco, Federico (2002): "El principio de seguridad jurídica: especial referencia a la certeza en la creación del Derecho", en: Documentación Administrativa, No 263264, pp. 21-72.

Comanducci, Paolo (2005): "Formas de (neo) constitucionalismo: un análisis metateórico", en Neoconstitucionalismo(s) M. Carbonell (edit.) Madrid: Trotta: p. 92-93.

Craig, Paul y de Búrca, Gráinne (2003): EU Law (Oxford, Oxford University Press, tercera edición) $1148 \mathrm{pp}$.

DiCEY, Albert Venn (1982): Introduction to the Study of the Law of the Constitution (Indianapolis, Liberty Fund) 435 pp.

Díez Sastre, Silvia (2012): "La responsabilidad por culpa en procedimientos competitivos", en La falta de servicio, Raúl Letelier (edit.): pp. 215-250.

Dorn Garrido, C. y Salinas Bruzzone, Carlos (2006): "La potestad invalidatoria en la ley de bases de procedimiento administrativo: una visión en perspectiva" en: Revista de Ciencias Sociales UV, $\mathrm{N}^{\circ}$ 51: pp. 259 y sgtes.

FErrada, Juan Carlos (2007): "La potestad invalidatoria de los órganos de la Administración del Estado, en VV.AA, Acto y procedimiento administrativo, en: Ediciones Universitarias de Valparaíso: pp. 131 y sgtes.

Ferrajoli, Luigi (2006): "Lo Stato di diritto fra passato e futuro", en Lo Stato di diritto, en Pietro Costa, Danilo Zolo (edits.), (Milano, Feltrinelli): p. 349-386. 
García de Enterría, Eduardo (2006): La Constitución como norma y el Tribunal Constitucional (Madrid, Civitas, cuarta edición) 324 pp.

García Luengo, J. (2002): El principio de protección de la confianza en el Derecho Administrativo (Madrid, Civitas) 512 pp.

García MaCho, Ricardo (1987): “Contenido y límites del principio de la confianza legítima: estudio sistemático en la jurisprudencia del Tribunal de Justicia”, en: Revista Española de Derecho Administrativo, No 56: pp. 557-572.

Gravitz, E. (1973): "Vertrauensschutz als Freihaitsschutz", en: Deutsches Verwaltungsblatt, No 18: pp. 675-684.

Hedemann, J.W. (1933): Die Flucht in die Generalklausen (Tubingen, Mohr, Gelbe OrBroschur).

Hierro Sánchez-Pescador, Liborio (1989): "Seguridad jurídica y actuación administrativa”, en: Documentación Administrativa, N²18-219.

HLOpHE, John (1990): "The doctrine of legitimate expectation and the Appellate Division", en: African Law Journal No 107: pp. 197-203.

Holmes, Stephen (2003): "Lineages of the Rule of Law", en Democracy and the Rule of Law, José María Maravall y Adam Przeworski (edits.), (Cambridge, Cambridge University Press): pp. 19-61.

IgARTÚA, Juan (1986): “Sobre 'principios' y 'positivismo legalista”, en RVAP, No 14: pp. $25-42$.

Immordino, María y ModicA, Carlo (2002): "El principio de seguridad jurídica en el ordenamiento jurídico italiano", en: Documentación Administrativa No 263-264: pp. 281 327.

Jara Schnettler, J. (2004): La nulidad de derecho público ante la doctrina y jurisprudencia (Santiago, Libromar).

Leguina Villa, Jesús (1987): "Principios Generales del Derecho y Constitución”, en Revista de Administración Pública, $\mathrm{N}^{\circ}$ 114: pp. 7-37.

LETELIER, Raúl (2002): “Un mal día no es eterno: seis alcances en materia de invalidación y nulidad de los actos administrativos", en: Revista de Derecho, Universidad de Concepción, Vol. 212, No 2: pp. 693-730.

Letelier, Raúl (2011): Nulidad y restablecimiento en procesos contra normas (Navarra, Civitas) $462 \mathrm{pp}$.

MaINKA, Johannes (1963): Vertrauensschutz im Öffentlichen Recht (Bohn, Röhrscheid) 82 pp.

Maravall, José María (2003): "The Rule of Law as a Political Weapon”, en Democracy and the Rule of Law, José María Maravall y Adam Przeworski (edits.), (Cambridge, Cambridge University Press): pp. 261-301.

Marín Vallejo, U. (2000): "Vigencia actual de la invalidación de los actos administrativos" en Revista de Derecho CDE, N²: pp. 45 a 60.

Martínez Roldan, L. (1988): “La seguridad jurídica: realidad o ilusión”, en Jornadas de Estudio sobre el Titulo Preliminar de la Constitución, tomo V (Madrid, Ministerio de Justicia, Secretaria General Técnica) pp. 3352-3353. 
Maurer, Hartmut (2004): Allgemeines Verwaltungsrecht (München, Beck, decimoquinta) 853 pp.

Medina Alcoz, Luis (2005): La responsabilidad patrimonial por acto administrativo (Navarra, Civitas) 459 pp.

Medina Alcoz, Luis (2006): "Confianza legítima y responsabilidad patrimonial”, en: Revista Española de Derecho Administrativo, N 130, pp. 275-326.

Merusi, Favio (1991): "Il principio di buona fede nel Diritto Amministrativo", en: Scritti per Mario Nigro. Problemi attuali di Diritto Amministrativo, vol. II, Milano, Giuffrè, pp. 217-224.

Millar, Javier (2003): "La potestad invalidatoria en la jurisprudencia nacional. Procedencia, alcance y limitaciones", en: Revista de Derecho, Universidad Austral de Chile, Vol. 14, pp. 83-97.

Morrone, Andrea (2001): Il custode della ragionevolezza (Milano, Giuffrè) 603 pp.

Olguín Juárez, H. (1961): Extinción de los actos administrativos. Revocación, Invalidación y Decaimiento (Santiago, Editorial Jurídica de Chile).

Oelckers Camus, O. (1978): "El principio de la autotutela administrativa como privilegio de la Administración Pública", en Revista de Derecho UCV, N² 2: pp. 121 y sgtes.

OssenbüHL, Fritz (1972): "Vertrauensschutz im sozialen Rechtsstaat", en: Die öffentliche Verwaltung, $\mathrm{N}^{\circ} 1-2$, pp. 25-36.

Pérez Luño, A. (1991): La seguridad juridica (Barcelona).

Pérez Luño, A. (1992) "La seguridad como función jurídica", en: Funciones y fines del derecho: Estudios en homenaje al profesor Mariano Hurtado Bautista (Murcia, Universidad de Murcia, Secretariado de Publicaciones): pp. 273-290.

Rebollo, Manuel (2002): "Nemo auditur propriam turpitudinem allegans en la jurisprudencia contencioso-administrativa”, en: Documentación Administrativa, No 185-221.

Reyes Riveros, J. (2002): La invalidación de actos administrativos (Santiago, ConoSur).

ShønberG, Soren (2000): Legitimate Expectations in Administrative Law (New York, Oxford University Press) $270 \mathrm{pp}$.

SCHWARZE, Jürgen (1992): European Administrative Law (London, Sweet and Maxwell) $1547 \mathrm{pp}$.

Soто Kloss, Eduardo (1989) "Invalidación de los actos administrativos", en Revista Chilena de Derecho, $\mathrm{N}^{\circ} 16$, pp. 475 y sgtes.

Tamanaha, Brian (2004): On the Rule of Law (Cambridge, Cambridge University Press) $180 \mathrm{pp}$.

VARGAS ZincKe, O. (1995) "Algunos aspectos sobre la invalidación en la Jurisprudencia de la Contraloría General de la República”, en: Gaceta Jurídica, n 178, pp. 35 y sgtes.

VV.AA. (2009): La primacía de la persona. Estudios en homenaje al profesor Eduardo Soto Kloss (Santiago, LegalPublishing) 1178 pp.

Wojcik RadKowska, C. (2001): "Entre seguridad jurídica y justicia: los conceptos de contenido variable”, en: Estudios de Deusto, vol. 49, No. 2: pp. 195-208.

Wolff, Hans; Bachof, Otto y Stober, Rolf (2004): Verwaltungsrecht (München, Beck, quinta edición) 938 pp. 
Zolo, Danilo (2006): "Teoria e critica dello Stato di diritto", en Lo Stato di diritto, en Pietro Costa, Danilo Zolo (edits.), (Milano, Feltrinelli): pp. 17-88.

\section{JURISPRUDENCIA CITADA}

Nacional

CMET con Min. de Transportes y Telecomunicaciones (2012): Corte Suprema, 30 de enero de 2012, Rol 7530-2009.

Agrícola y Comercial Las Araucarias Limitada con I. Municipalidad de San Esteban (2013), Corte Suprema de16 de mayo de 2013, Rol 664-2012.

Vásquez con I. Municipalidad de Osorno (2013): Corte Suprema, 14 de mayo de 2013, Rol 12195-2011.

\section{Extranjera}

Northern Securities Co. v. United States [1904] 193 U.S. 197.

Arrêt Dame Cachet, 3 de noviembre de 1922.

C-7/56 y 3-7/57 Algera v. Common Assembly [1957] ECR 39.

Oberverwaltungsgericht, Die öffentliche Verwaltung (DÖV) 1957, № 27, pp. 753-756.

C-14/61 Hoogovens v. High Authority [1962] ECR 253.

Schmidt v. Home Secretary (1969) 2 Ch. 149.

Dorset Yatch Co vs. Home Office [1970] AC 1004.

C-2/75 Einfuhr-und Vorratsstelle für Getreide und Futtermittel v. C. Mackprang [1975] ECR 607.

C-52/81 Offene Handelsgesellschaft in Firma Werner Faust v. Comisión de las Comunidades Europeas [1982] ECR 3745.

C-159/82 Verli-Wallace v. Commission [1983] ECR 2711.

C-265/85 Van den Bergh v. Commission of the European Communities [1987] ECR 1155.

Hill vs. Chief Constable of West Yorkshire [1989] AC 53.

C-331/88 The Queen v. Minister of Agriculture, Fisheries and Food and Secretary of State for Health, ex parte: Fedesa and others [1990] ECR 4023.

C-152/88 Sofrimport Sàrl v. Commission [1990] ECR 2477.

C-350/88 Société française des Biscuits Delacre v. Commission of the European Communities [1990] ECR 395.

T-336/94 Efisol v. Commission [1996] ECR II-1343.

C-110/97 Netherlands v. Council [1997] ECR 1795

C-104/97P Atlanta AGv. Commission and Council [1999] ECR 6983.

C-402/98 ATB v. Ministero per le Politiche Agricole [2000] ECR 5501.

Arrêt Termon, 26 de octubre de 2001.

C-179/00 Gerald Weidacher v. Bundesminister für Land- und Forstwirtschaft [2002] ECR 501. 